\title{
OPERACIONALIZAÇÃO DO CONCEITO DE CLASSE SOCIAL EM ESTUDOS EPIDEMIOLÓGICOS*
}

\author{
Cintia Lombardi** \\ Mario Bronfman*** \\ Luiz A. Facchini** \\ Cesar G. Victora** \\ Fernando C. Barros** \\ Jorge U. Béria** \\ Ana M.B. Teixeira**
}

\begin{abstract}
LOMBARDI, C. et al. Operacionalizaçăo do conceito de classe social em estudos epidemiológicos. Rev. Saúde públ., S. Paulo, 22:253-65, 1988.

RESUMO: Procura-se demonstrar que é possivel operacionalizar o conceito de classe social de forma a utilizá-lo em estudos epidemiológicos. Foi adaptado às características da formaçăo social de Pelotas, RS (Brasil), modelo de classificação desenvolvido para o México e comparado com o desenvolvido para Ribeirão Preto, SP (Brasil). Mediu-se o poder discriminatório das duas classificaçøes em termos do processo saúde-doença, tendo como variável dependente o crescimento de 5.384 crianças nascidas em 1982. As duas classificaçðes estão associadas com diferenças significativas $(P<0,001)$ no crescimento infantil, mas o modelo do México mostra melhor poder discriminatório do que a classificação de Ribeirão Preto. Quando ambas foram incluídas em uma análise multivariada do peso e da altura das crianças, 0 efeito do modelo do México foi altamente significativo $(P<0,001)$, ao contrário do efeito da classificação, modelo Ribeirão Preto.
\end{abstract}

UNITERMOS: Classe social. Métodos epidemiológicos. Inquéritos epidemiológicos. Crescimento. Criança.

\section{INTRODUÇÃO}

Há pelo menos vinte anos questiona-se o paradigma dominante da epidemiologia que conceitua a doença como um fenômeno biológico individual. Este questionamento implicou modificaçoes conceituais e metodológicas. Entre as primeiras destacam-se os estudos que utilizam o conceito de classe social para explicar os fenômenos de saúde-doença, muitos dos quais realizados na América Latina ${ }^{1,3-8,14}$. Segundo Bronfman e Tuirán', "a inserção de classe determina, em última instância, $O$ acesso diferencial, entre outros, à infra-estrutura de saúde, à quantidade e qualidade de alimentos, à habitação e ao vestuário".

Uma primeira dificuldade na incorporação do conceito de classe social em estudos epidemiológicos é o fato de que o mesmo tem recebido diferentes interpretações. Uma dificuldade adicional é a operacionalização desse conceito, a fim de classificar os indivíduos ou familias através de questionários padronizados.

A definição de classe social na qual se baseou foi a seguinte: "Las clases son grandes grupos de hombres que se diferencian entre sí por el lugar que ocupan en un sistema de produción históricamente determinado, por las relaciones en que se encuentran con respecto a los medios de produción (relaciones que en gran parte quedan establecidas y formuladas por las leyes), por el papel que desempeñan en la organización social del trabajo y, consiguientemente, por el modo y la proporción en que perciben la parte de riqueza social de que disponen. Las clases son grupos humanos, uno de los quales puede apropiar-se del trabajo del otro, por ocupar puestos diferentes en un régimen determinado de economia social"' (Lenin').

O conceito de classe engloba, portanto, diferentes instâncias (econômica, jurídico-política e ideológica) que compóe o todo social ${ }^{10}$. As limi-

* Investigaçăo patrocinada pelo "International Development Research Centre" do Canadá e pelo "Overseas Development Administration" do Reino Unido.

** Departamento de Medicina Social da Faculdade de Medicina da Universidade Federal de Pelotas - Caixa Postal 464 96001 - Pelotas, RS - Brasil.

*** Centro de Estúdios Demográficos y de Desarrollo Urbano de El Colegio de Mexico - Camino al Ajusco, 20 - 01000 México, DF - México. 
taçðes impóstas pela técnica de entrevistas através de questionários e as dificuldades metodológicas de delinear indicadores confiáveis sobre a consciência e a prática política das classes tornam praticamente impossivel a tarefa de operacionalizar o conteúdo integral do conceito, obrigando a restringir o mesmo ao nível da instância econômica. Assim, "os questionários não permitem apreender as classes em sua totalidade, ou seja, em suas mutaçōes internas e em suas relações com as outras classes e com a sua estrutura social. No entanto, é possível identificar grupos sociais e assim definir a "situação de classe" e a forma pela qual esta afeta o comportamento dos indivíduos" (Bronfman e Tuirán ${ }^{\text {) }}$.

Com base em estudo epidemiológico sobre saúde infantil realizado em Pelotas, RS ${ }^{15,16}$, o presente artigo objetiva mostrar que é possivel operacionalizar o conceito de classe social para sua utilização em estudos epidemiológicos.

\section{POPULAÇÃo E MÉTODOS}

\subsection{Trabalho de Campo}

Entre dezembro de 1985 e abril de 1986, foram visitados todos os domicílios da cidade de Pelotas, RS (aproximadamente 77.000) para localizar crianças nascidas em 1982. Foram identificadas 5.384 crianças, com idade entre 35 e 52 meses. Este estudo transversal corresponde a uma das etapas do estudo longitudinal das crianças nascidas em Pelotas, em 1982 $2^{15,16}$.

Nessas entrevistas, além de dados demográficos, de morbidade, desenvolvimento psicológico, uso de medicamentos e de serviços de saúde, foram coletadas diversas informações sócio-econômicas.

As crianças foram pesadas sem roupas com balanças tipo Salter com precisão até $100 \mathrm{~g}$, e sua estatura foi medida com antropômetros portáteis. A análise estatística dos indicadores de crescimento conforme a classe social foi feita através de análise de covariância" ${ }^{1 !}$.

\subsection{Classificação das Famílias Conforme a Classe Social}

\subsubsection{Classificação de Barros}

$\mathrm{Na}$ primeira tentativa de operacionalização do conceito de classe social foi utilizado o esquema elaborado por Barros', baseado na análise de Singer ${ }^{12}$. Nesse esquema, Barros' utilizou as informaçōes sobre posição na ocupação (como por exemplo, empregado, empregador, au- tônomo), tipo de ocupação (como por exemplo, pedreiro, motorista, ou empregada doméstica), renda e número de empregados.

$\mathrm{Na}$ utilização dessa classificação, foram encontradas algumas dificuldades. O principal problema diz respeito aos critérios de entrada no esquema, que não são excludentes. Tomando como exemplo os assalariados, cujo critério básico de ingresso é a posição na ocupação, pode-se classificá-los tanto de acordo com o tipo de ocupação, como também de acordo com o ramo de atividade (para aqueles que trabalham na construção civil ou na agricultura), dando assim margem a dúvidas. Um exemplo seria um assalariado permanente de empresa agrícola com conhecimento de ofício (tratorista, operador de máquina, ou mecânico), o qual seria classificado como subproletário, em função do ramo a que pertence.

Outra dificuldade encontrada foi em relação a autônomos sem estabelecimento, que são classificados diretamente como subproletários sem levar em conta sua formação ou conhecimento de ofício. Assim, um profissional liberal (de nível universitário), sendo autônomo sem estabelecimento próprio poderia ser considerado como subproletário. Este seria também o caso de trabalhadores autônomos qualificados, como artesãos, mecânicos, serralheiros ou eletricistas, que prestem serviços e não possuam estabelecimento.

Uma terceira dificuldade diz respeito à classificação dos indivíduos fora da População Economicamente Ativa (PEA) como subproletários. Uma dona-de-casa ou um estudante que não exerçam atividades remuneradas, e sejam sustentados por terceiros, podem ser na verdade integrantes de qualquer classe, dependendo da inserção de classe do responsável pelo seu sustento.

Tendo em vista as ambiguidades e contradições resultantes da aplicação desse esquema, decidiu-se adotar uma nova classificação. Os problemas com a classificação original fizeram com que fosse posteriormente modificada ${ }^{2}$, mas versão anterior ${ }^{1}$ continua sendo utilizada em levantamentos epidemiológicos por haver recebido maior divulgação do que sua revisão.

\subsubsection{Classificação proposta}

Optou-se por adaptar uma classificação desenvolvida por Bronfman e Tuirán ${ }^{5}$ em função da "Encuesta Nacional Demográfica", México, 1982, onde se buscou operacionalizar o conceito de classe social. Naquela investigaçãos, coletou-se uma grande variedade de indi- 
cadores, permitindo, assim, a construção de diversos grupos, classes ou agregados, agrícolas e não agrícolas. Para sua utilização em Pelotas, foi necessário adaptá-la tanto às características sócio-econômicas locais quanto aos indicadores disponiveis no estudo.

A Tabela 1 resume a relação entre cada uma das dimensões contidas na definição de classe social, as variáveis em que podem ser decom- postas e os indicadores que, no estudo longitudinal de Pelotas ${ }^{15,16}$, foram usadas para medi-las. A situação de classe da família foi definida através da inserção, nos processos de produção, circulação ou coadjuvantes, de seu componente que recebia a maior renda. Quando a maior renda provinha de um individuo que não convivia com a familia, a classe social deste era a considerada.

TABELA 1

Dimensões da operacionalização do conceito de classe social: variáveis e indicadores utilizados em Pelotas.

\begin{tabular}{ll}
\hline \multicolumn{1}{c}{ Variáveis } & \multicolumn{1}{c}{ Indicadores } \\
\hline Primeira Dimensão: lugar que ocupa em um sistema de produção historicamente determinado \\
\hline Condição de atividade. & $\begin{array}{l}\text { Atividade no momento } \\
\text { (trabalhando, desempregado, } \\
\text { aposentado, etc.) } \\
\text { Atividade do estabelecimento } \\
\text { empresa, negócio ou instituição. }\end{array}$ \\
Retor de atividade. & $\begin{array}{l}\text { Idem. } \\
\text { Nome da ocupação e tarefas mais } \\
\text { Tipo de atividade. }\end{array}$ \\
importantes que desenvolve. \\
Posição na ocupação. & $\begin{array}{l}\text { Posição na ocupação. } \\
\text { Número de trabalhadores que } \\
\text { trabalho. }\end{array}$ \\
\hline
\end{tabular}

Segunda Dimensão: relação com os meios de produção.

Propriedade dos meios Propriedade dos meios de produção. de produçáo.

Terceira Dimensão: papel na organização social do trabalho.

\begin{tabular}{ll}
\hline Formação da força & \\
de trabalho. & \\
$\begin{array}{ll}\text { a. Escolaridade. } & \text { Nível de escolaridade. } \\
\text { b. Conhecimento } & \text { Tipo de ocupação. } \\
\text { de ofício. } & \end{array}$
\end{tabular}

Quarta Dimensão: magnitude e forma em que recebem a parte da riqueza social de que
dispóe.

Magnitude do salário.

Magnitude de outras

fontes de renda.
Montante do salário.

Montante de rendimentos oriundos de outras fontes de renda.

Obs.: Adaptado de Bronfman e Tuirán 5 . 
As famílias foram classificadas como pertencentes a uma das seguintes classes sociais:
a) burguesia;
b) nova pequena burguesia;
c) pequena burguesia tradicional;
d) proletariado não típico;
e) proletariado típico; e
f) subproletariado.

A composição destas classes é descrita no Anexo $1 \mathrm{e}$ os esquemas classificatórios são apresentados nas Figs. 1, 2, 3. O critério de entrada nos esquemas é, fundamentalmente, a relação com os meios de produção, sendo as demais variáveis utilizadas a partir deste ponto. As alterações efetuadas em relação ao modelo de Bronfman e Tuirán são comentadas no Anexo 2 e a definição dos termos utilizados constitui o Anexo 3.

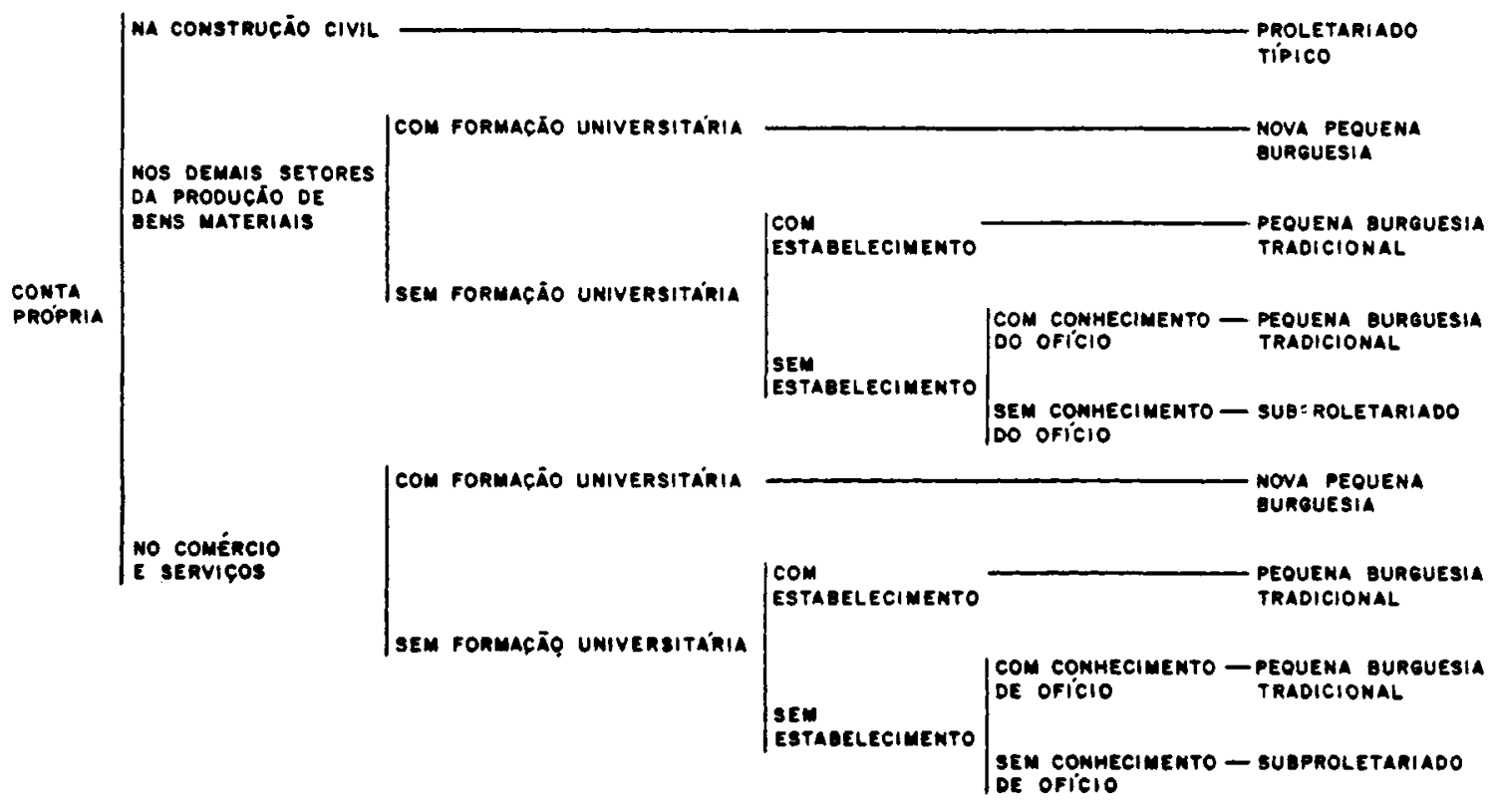

Fig. 1 - Esquema de operacionalizaçăo de nova pequena burguesia, pequena burguesia tradicional, proletariado típico e subproletariado.

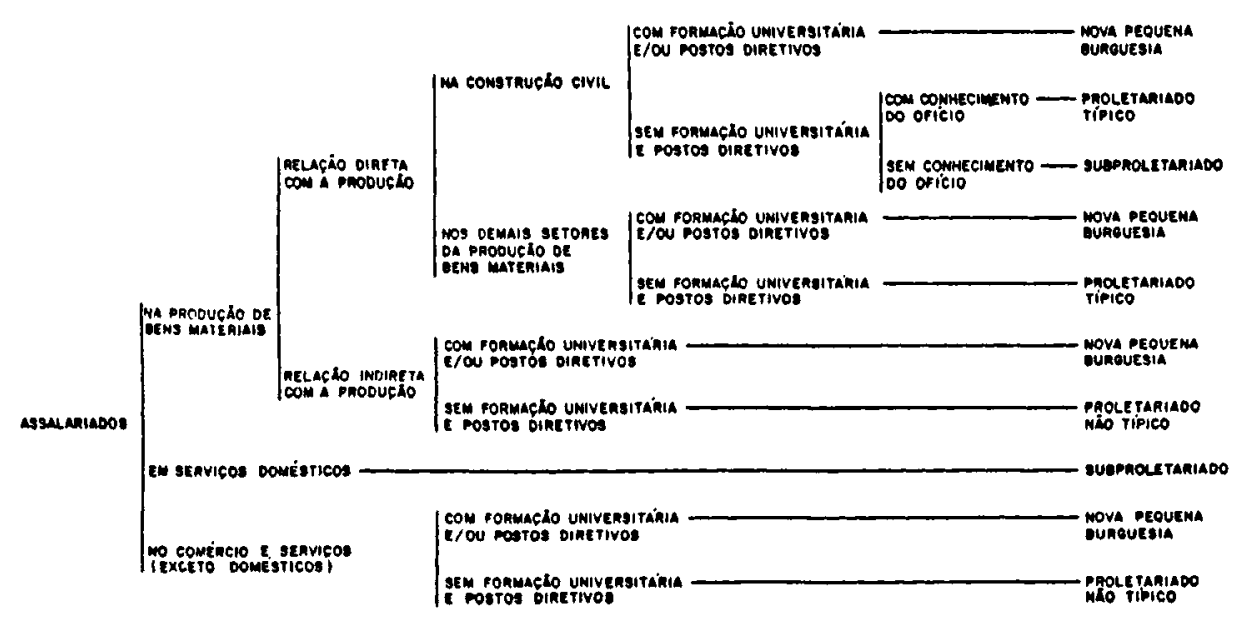

Fig. 2 - Esquema de operacionalização da nova pequena burguesia, proletariado não típico, proletariado típico e subproletariado. 


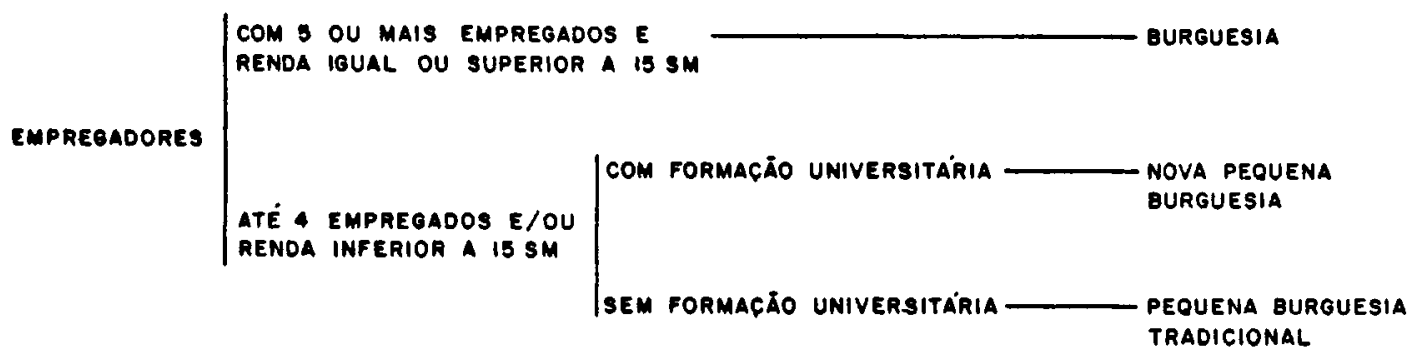

Fig. 3 - Esquema de operacionalização da burguesia, nova pequena burguesia e pequena burguesia tradicional.

\section{RESULTADOS}

\subsection{Comparação Entre as Duas Classificações}

A Tabela 2 mostra as diferenças entre as duas classificações. O grupo que mais sofreu alterações foi o subproletariado, que segundo a classificação de Barros ${ }^{1}$ estaria superestimado, com 1.451 famílias ( $27 \%$ do total), sendo reduzido na atual classificação e 541 famílias $(10,1 \%)$. Ambos os esquemas classificaram como subproletários os serventes na construção, empregados domésticos, lenhadores, pescadores, condutores de veículos de tração animal (freteiros), trabalhadores com ocupaçð̄es variadas (biscateiros) e outras categorias menos numerosas. Por outro lado, a classificação de Barros ${ }^{1}$ incluiu no subproletariado grupos que, a nosso ver, pertencem a outras classes sociais: a) trabalhadores na agricultura (capatazes, operadores de máquinas, peðes, etc.) e mestres e oficiais da construção civil, que, segundo a presente classificação, pertencem ao proletariado não típico;

b) trabalhadores administrativos empregados na construção civil e na agricultura; incluídos em proletariado não típico; e

c) trabalhadores autônomos, sem estabelecimento, que possuem conhecimento de oficio, tais como artesãos, representantes de vendas e trabalhadores em serviços de manutenção (de veículos automotores, de aparelhos elétrico-eletrônicos, etc.); classificados como pequena burguesia tradicional.

A principal alteração ocorrida no proletariado diz respeito à distinção entre proletariado típico e não-típico (Tabela 2), sendo este último

TABELA 2

Distribuição dos chefes de família segundo o modelo de Barros * e o modelo proposto, Pelotas, 1986

\begin{tabular}{|c|c|c|c|c|c|c|c|c|}
\hline \multirow{2}{*}{$\begin{array}{l}\text { Classe social } \\
\text { (Barros*) }\end{array}$} & \multicolumn{6}{|c|}{ Classe social (classificação proposta) } & \multirow[b]{2}{*}{$\begin{array}{c}\text { Não } \\
\text { classificados }\end{array}$} & \multirow[b]{2}{*}{ Todas } \\
\hline & $\begin{array}{c}\text { Sub- } \\
\text { proletariado }\end{array}$ & $\begin{array}{c}\text { Proletariado } \\
\text { típico }\end{array}$ & $\begin{array}{l}\text { Proletariado } \\
\text { não típico }\end{array}$ & $\begin{array}{c}\text { Pequena } \\
\text { burguesia } \\
\text { tradicional }\end{array}$ & $\begin{array}{c}\text { Nova } \\
\text { pequena } \\
\text { burguesia }\end{array}$ & Burguesia & & \\
\hline Subproletariado & 519 & 570 & 55 & 234 & 5 & - & 68 & $\begin{array}{c}1451 \\
270\end{array}$ \\
\hline Proletariado & 19 & 820 & 2161 & 6 & 102 & 2 & 5 & $\begin{array}{c}3115 \\
58,0\end{array}$ \\
\hline $\begin{array}{l}\text { Pequena } \\
\text { burguesia }\end{array}$ & 3 & 1 & 4 & 491 & 9 & 2 & 1 & $\begin{array}{l}511 \\
9,5\end{array}$ \\
\hline $\begin{array}{l}\text { Burguesia } \\
\text { gerencial }\end{array}$ & - & - & 4 & - & 222 & 2 & - & $\begin{array}{r}228 \\
4,2\end{array}$ \\
\hline $\begin{array}{l}\text { Burguesia } \\
\text { empresarial }\end{array}$ & - & - & - & 8 & 3 & 58 & - & $\begin{array}{l}69 \\
1,3\end{array}$ \\
\hline $\begin{array}{ll}\text { Todas } & \mathbf{N} \\
& \%\end{array}$ & $\begin{array}{l}541 \\
10,1\end{array}$ & $\begin{array}{r}1391 \\
25,9\end{array}$ & $\begin{array}{r}2224 \\
41,4\end{array}$ & $\begin{array}{l}739 \\
13,8\end{array}$ & $\begin{array}{r}341 \\
6,3\end{array}$ & $\begin{array}{c}64 \\
1,2\end{array}$ & $\begin{array}{l}74 \\
1,4\end{array}$ & $\begin{array}{l}5374 \\
100,0\end{array}$ \\
\hline
\end{tabular}

* $\operatorname{Barros}^{1}$ (1986). 
mais numeroso. O proletariado como um todo aumentou devido, principalmente, ao ingresso de individuos anteriormente classificados como subproletários. Além disso, foi incluído na nova pequena burguesia o grupo constituído por profissionais de nível superior e por professores universitários, que, ao se utilizar a classificação de Barros ${ }^{1}$ foi enquadrado em proletariado, já que não parecia coerente classificá-los em burguesia gerencial.

Não houve alteraçōes substanciais, em termos numéricos, em relação à classificação da pequena burguesia, burguesia gerencial e burguesia empresarial. A pequena burguesia passa a denominar-se pequena burguesia tradicional, a burguesia gerencial passa a ser nova pequena burguesia, e a burguesia empresarial, burguesia. Estas mudanças não representam apenas alterações de nomenclatura, mas sim uma diferença de concepções teóricas.

A nosso ver, porém, tanto os indivíduos que exercem funçōes próprias do capital quanto os que ocupam postos de alto nivel técnico devem ser considerados como componentes da fração de classe denominada nova pequena burguesia, pois como não são proprietários dos meios de produção não podem estar incluídos na burguesia. Na utilização do modelo atual observou-se redução relativa na composição da burguesia de $5,8 \%$ para $1,2 \%$, proporção esta que parece estar mais em consonância com a atual etapa de alta concentração do capital.

\subsection{Avaliação Empírica}

Para testar empiricamente qual dos dois modelos possuiria maior poder discriminatório em termos do processo saúde-doença na infância, decidiu-se comparar o crescimento de crianças pertencentes a famílias com diferentes situaçðes de classe. $O$ crescimento foi escolhido por sintetizar a ação de diversos fatores - nutricionais, ambientais, e assistenciais - que em última análise dependem da inserção de classe da família. As Tabelas 3 e 4 mostram os dados referentes ao peso e à altura das crianças estudadas, após ajuste para idade e sexo através de análise de covariância (a idade média das 5.384 crianças foi 43,1 meses e o desvio padrão 3,7 meses).

TABELA 3

Médias de peso de crianças de 35 a 52 meses, ajustadas para idade e sexo.

Comparação da classificação de Barros* e da proposta no presente trabalho. Pelotas, 1986.

\begin{tabular}{|c|c|c|c|c|c|c|c|}
\hline \multirow[b]{2}{*}{$\begin{array}{l}\text { Classe social } \\
\text { (Barros*) }\end{array}$} & \multicolumn{6}{|c|}{ Classe social (classificação proposta) } & \multirow[b]{2}{*}{ Todas } \\
\hline & $\begin{array}{c}\text { Sub- } \\
\text { proletariado }\end{array}$ & $\begin{array}{l}\text { Proletariado } \\
\text { típico }\end{array}$ & $\begin{array}{l}\text { Poletariado } \\
\text { não típico }\end{array}$ & $\begin{array}{c}\text { Pequena } \\
\text { burguesia } \\
\text { tradicional }\end{array}$ & $\begin{array}{c}\text { Nova } \\
\text { pequena } \\
\text { burguesia }\end{array}$ & Burguesia & \\
\hline Subproletariado & 14,70 & 14,93 & 15,31 & 15,82 & - & - & 15,02 \\
\hline Proletariado & 14,87 & 15,03 & 15,71 & - & 16,73 & - & 15,48 \\
\hline $\begin{array}{l}\text { Pequena } \\
\text { burguesia }\end{array}$ & - & - & - & 16,05 & - & - & 16,09 \\
\hline $\begin{array}{l}\text { Burguesia } \\
\text { gerencial }\end{array}$ & - & - & - & - & 16,47 & - & 16,49 \\
\hline $\begin{array}{l}\text { Burguesia } \\
\text { empresarial }\end{array}$ & - & - & - & - & - & 16,79 & 16,71 \\
\hline Todas & 14,73 & 14,99 & 15,71 & 15,97 & 16,52 & 16,67 & 15,52 \\
\hline
\end{tabular}

* $\operatorname{Barros}^{1}(1986)$

Obs.: 68 crianças foram classificadas como pertencentes ao subproletariado (Barros ${ }^{1}$ ) e como não classificáveis (classificação proposta). Sua média de peso foi $15,30 \mathrm{~kg}$.

Nāo foram calculadas as médias para as células com menos de 10 crianças. 


\section{TABELA 4}

Médias de altura de crianças de 35 a 52 meses, ajustadas para idade e sexo. Comparação da classificação de Barros* e da proposta no presente trabalho). Pelotas, 1986.

\begin{tabular}{|c|c|c|c|c|c|c|c|}
\hline \multirow[b]{2}{*}{$\begin{array}{l}\text { Classe social } \\
\text { (Barros*) }\end{array}$} & \multicolumn{6}{|c|}{ Classe social (classificação proposta) } & \multirow[b]{2}{*}{ Todas } \\
\hline & $\begin{array}{l}\text { Sub- } \\
\text { proletariado }\end{array}$ & $\begin{array}{c}\text { Proletariado } \\
\text { típico }\end{array}$ & $\begin{array}{l}\text { Proletariado } \\
\text { não típico }\end{array}$ & $\begin{array}{c}\text { Pequena } \\
\text { burguesia } \\
\text { tradicional }\end{array}$ & $\begin{array}{c}\text { Nova } \\
\text { pequena } \\
\text { burguesia }\end{array}$ & Burguesia & \\
\hline Subproletariado & 95,3 & 96,1 & 97,3 & 98,1 & - & - & 96,2 \\
\hline Prole tariado & 94,9 & 96,3 & 97,9 & - & 100,3 & - & 97,3 \\
\hline $\begin{array}{l}\text { Pequena } \\
\quad \text { burguesia }\end{array}$ & - & - & - & 98,4 & - & - & 98,4 \\
\hline Burguesia & - & - & - & - & 99,8 & - & 99,8 \\
\hline $\begin{array}{l}\text { Burguesia } \\
\text { empresarial }\end{array}$ & - & - & - & - & - & 100,2 & 100,1 \\
\hline Todas & 95,4 & 96,2 & 97,9 & 98,3 & 99,8 & 100,1 & 97,4 \\
\hline
\end{tabular}

* Barros $^{1}$ (1986)

Obs.: 68 crianças foram classificadas como pertencentes ao subproletariado (Barros ${ }^{1}$ ) e como não classificáveis (classificação proposta). Sua média de altura foi $97 \mathrm{~cm}$.

Não foram calculadas as médias para as células com menos de 10 crianças.

As duas classificações estão associadas com diferenças significativas $(P<0,001)$ no crescimento infantil, mas o esquema proposto mostra que as crianças do subproletariado e do proletariado típico apresentam crescimento inferior ao que seria estimado pela classificação de Barros ${ }^{1}$. Por exemplo, as crianças do subproletariado, segundo o presente modelo, têm em média $14,73 \mathrm{~kg}$ e $95,4 \mathrm{~cm}$ (erros-padrão $0,09 \mathrm{~kg}$ e $0,23 \mathrm{~cm}$ ), enquanto que de acordo com o modelo anterior teriam $15,02 \mathrm{~kg}$ e $96,2 \mathrm{~cm}$ (erros-padrão $0,06 \mathrm{~kg}$ e $0,13 \mathrm{~cm}$ ). Embora estas diferenças possam parecer pequenas, os erros-padrão das estimativas são muito reduzidos.

As crianças que mudaram de categoria são, em geral, mais parecidas com aquelas de sua nova categoria do que com as de sua categoria anterior. Por exemplo, as crianças classificadas por Barros como pertencentes ao subproletariado e por nós como da pequena burguesia tradicional possuem em média $15,82 \mathrm{~kg} \mathrm{e} 98,1 \mathrm{~cm}$, valores muito mais próximos aos da pequena burguesia tradicional do que aos do subproletariado.

Esta comparação do poder discriminatório das duas classificações foi complementada através de uma análise de covariância (Tabela 5) em que, após o ajuste para idade e sexo, foram incluídas ao mesmo tempo as duas classificações de classe social. Quando isto aconteceu, o efeito da classificação de Barros ${ }^{1}$ deixou de ser estatisticamente significativo, enquanto que $o$ efeito da atual classificação foi altamente significativo $(\mathbf{P}<0,001)$ tanto para o peso quanto para a altura.

\section{DISCUSSÃO}

O presente artigo procura contribuir para o debate sobre a operacionalização do conceito de classe social. Embora este processo deixe de lado as dimensões jurídico-política e ideológica do conceito e concentre-se na dimensão econômica, acredita-se que as vantagens de poder incluí-lo em estudos epidemiológicos superam, em muito, suas limitações.

Considera-se que, somente através do desenvolvimento cada vez mais rigoroso dos modelos de operacionalização de classe social, poder-se-á captar a situação de classe dos grupos sociais e a forma em que esta afeta a saúde dos indivíduos que a compartem em determinada formação econômico-social. Isto por que os indicadores tradicionais de estratificação, como renda e escolaridade, mesmo nas tentativas de sua utilização a partir de uma perspectiva dialética, configuram grupos humanos gue não compartilham necessariamente a mesma situação de classe, já que implicam cortes arbitrários do pesquisador que não refletem a complexidade da estrutura social ${ }^{13}$. Neste contexto, consideramos que trabalhos como o de Singer ${ }^{12} \mathrm{e}$ 
TABELA 5

Análise de covariância para investigar o poder discriminatório das duas classificaçớes em relação ao peso e à altura das crianças. Pelotas, 1986.

\begin{tabular}{|c|c|c|c|c|c|}
\hline Fonte de variação & Soma dos quadrados & Graus de liberdade & Quadrado médio & $\mathrm{F}$ & $\mathbf{P}$ \\
\hline \multicolumn{6}{|l|}{ Peso } \\
\hline \multicolumn{6}{|l|}{ Classificação } \\
\hline $\begin{array}{l}\text { Proposta } \\
\text { Barros* }\end{array}$ & $\begin{array}{r}576,35 \\
33,96\end{array}$ & $\begin{array}{l}5 \\
4\end{array}$ & $\begin{array}{r}115,27 \\
8,49\end{array}$ & $\begin{array}{r}25,16 \\
1,85\end{array}$ & $\begin{array}{c}<0,001 \\
0,12\end{array}$ \\
\hline $\begin{aligned} \text { Covariáveis: Idade } & \\
& \text { Sexo }\end{aligned}$ & $\begin{array}{r}2426,26 \\
210,34\end{array}$ & $\begin{array}{l}1 \\
1\end{array}$ & $\begin{array}{r}2426,26 \\
210,34\end{array}$ & $\begin{array}{r}529,62 \\
45,92\end{array}$ & $\begin{array}{l}<0,001 \\
<0,001\end{array}$ \\
\hline \multicolumn{6}{|l|}{ Altura } \\
\hline \multicolumn{6}{|l|}{ Classificação } \\
\hline $\begin{array}{l}\text { Proposta } \\
\text { Barros* }\end{array}$ & $\begin{array}{r}3395,55 \\
82,85\end{array}$ & $\begin{array}{l}5 \\
4\end{array}$ & $\begin{array}{r}679,11 \\
20,71\end{array}$ & $\begin{array}{r}35,80 \\
1,09\end{array}$ & $\begin{array}{c}<0,001 \\
0,36\end{array}$ \\
\hline $\begin{aligned} & \text { Covariáveis: Idade } \\
& \text { Sexo }\end{aligned}$ & $\begin{array}{r}28809,09 \\
906,33\end{array}$ & $\begin{array}{l}1 \\
1\end{array}$ & $\begin{array}{r}28809,09 \\
906,33\end{array}$ & $\begin{array}{r}1518,59 \\
47,78\end{array}$ & $\begin{array}{l}<0,001 \\
<0,001\end{array}$ \\
\hline
\end{tabular}

* $\operatorname{Barros}^{1}(1986)$

Barros ${ }^{1,2}$ representam um grande avanço no entendimento da composição de classes do Brasil e na operacionalização deste conceito.

Neste procedimento, pelo menos três pontos são fundamentais: os aspectos teórico-conceitual e o metodológico, e a adequação às características da formação sócio-econômica. Partindo-se do mesmo conceito pode-se chegar a interpretações diferentes e portanto a distintos modelos de operacionalização, como exemplificam os vários estudos sobre o tema realizados na América Latina ${ }^{1,3,8,14}$. Além dessas diferenças teórico-conceituais, devem ser consideradas as peculiaridades de cada estrutura social na escolha e/ou na construção de um modelo. Portanto, ao ser utilizada classe social como categoria analítica, em estudos epidemiológicos, acredita-se que, levando-se em conta estes três pontos, tornar-se-á possível passar do plano teórico para o empírico.

A comparação do poder discriminatório das duas classificações ilustra a possibilidade de validação empírica do processo de operacionalização. Em primeiro lugar, deve-se escolher um aspecto do processo saúde-doença - como o crescimento humano - em relação ao qual esperar-se-ia encontrar importantes diferenciais entre as classes. A seguir, é possível testar o poder discriminatório de um ou mais esquemas propostos e validá-los. Se os resultados forem insatisfatórios, pode-se então retornar ao estudo teórico para investigar possíveis equívocos na operacionalização do conceito. Sem desejar reduzir o entendimento do processo saúde-doença a um enfoque meramente empírico, acredita-se que a presente proposta ilustra como, a partir de uma discussão cuidadosa, é possível testar uma proposta de operacionalização, $\mathrm{e}$, se for o caso, retornar à discussão com a contribuição dos resultados obtidos.

Finalmente, cabe também salientar que, sem o entendimento e a aplicação adequadas do método epidemiológico, a proposta validação empírica pode levar a resultados errôneos. Desta forma, a colaboração de profissionais com distintas formações - sociólogos, epidemiologistas, economistas, entre outros - é fundamental para levar a cabo essas tentativas de operacionalizar o conceito de classe social na pesquisa epidemiológica. 
LOMBARDI, C. et al. [The operationalization of the concept of social class in epidemiological studies]. Rev. Saúde públ., S. Paulo, 22:253-65, 1988.

ABSTRACT: The development of an operational classification of the Marxist concept of social class that could be used in epidemiological studies is attempted. Although such a classification will necessarily be restricted to the economic dimension of the concept, and leave aside its ideological and legal-political components, it is believed that it may lead to a better understanding of the distribution of ill-health in a given population. Two classifications are described - that developed in Ribeirão Preto, S. Paulo (Brazil), and a new classification based on work done in Mexico. These are compared in terms of how closely associated they are with the patterns of growth of 5,384 young children in the city of Pelotas in Southern Brazil. It is concluded that the proposed classification has greater power of discrimination in terms of child growth than that previously proposed.

UNITERMS: Social class. Epidemiologic methods. Health surveys. Growth. Child.

\section{REFERENCIAS BIBLIOGRÁFICAS}

1. BARROS, M.B.A. A utilização do conceito de classe social nos estudos dos perfis epidemiológicos: uma proposta. Rev. Saúde públ., S. Paulo, 20:269-73, 1986.

2. BARROS, M.B.A. Mortalidade e classe social: uma proposta de investigação. In: Seminário Latino-Americano sobre População e Saúde, Campinas 1985.Anais. Campinas, Ed. Unicamp, 1986. v.1., p. 357-67.

3. BEHM, H. Socioeconomic determinants of mortality in Latin America. In: Meeting on Socioeconomic Determinants and Consequences of Mortality, Mexico City, 1979. Proceedings. New York, United Nations, 1980. p. 140-65.

4. BREILH, J.; GRANDA, E.; CAMPAÑA, A.; BETANCOURT, $O$. Clase social y desigualdad ante la muerte en Quito. In: Breilh, J.; Granda, E.; Campana, A. \& Betancourt, O. Ciudad y muerte infantil. Quito, CEAS, 1983. p. 83-124.

5. BRONFMAN, M. \& TUIRÁN, R. La desigualdad ante la muerte: clases sociales y mortalidad en la niñez. Cuad. méd.-soc., Rosario, (29/30):53-75, 1984.

6. CAMPANARIO, P. \& SEGOVIA, M. Las clases sociales y el comportamiento reproductivo en Costa Ri$c a$. San José, Centro Latinoamericano de Demografia, 1978.

7. DIERCKXSENS, W. Capitalismo y población. San Jose, Ed. Universitária Centroamericana, 1982.

8. GÓMEZ, M. Fecundidad, anticoncepcion y clases sociales. In: Seminario Nacional de Demografia, 7:, San José, 1979. San José, Universidad de Costa Rica, 1979. p. 71-100.
9. LENIN, V.I. Una gran iniciativa. In: Obras completas. Moscou, Ed. Progreso, 1957. T. II. p. 162.

10. MARX, K. Introdución general a la critica de la economia politica. México, Ed. Pasado y Presente, 1982.

11. NORUSIS, M.J. SPSS $/ P C+$ - Statistical Package for the Social Sciences. Chicago, SPSS Inc., 1986.

12. SINGER, P.I. Dominação e desigualdade: estrutura de classes e repartição de renda no Brasil. Rio de Janeiro, Ed. Paz e Terra, 1981.

13. STAVENHAGEN, R. Estratificação social e estrutura de classes. In: Velho O.C.; Palmeira M.G.S.; Bertelli, A.R., org. Estrutura de classes e estratificação social. 9. ed. Rio de Janeiro, Zahar, 1981. p. 133-70.

14. TORRADO, S. Clases sociales, familia y comportamiento demográfico: orientaciones metodológicas. Démogr. Econ., México, 12:343-76, 1978.

15. VICTORA, C.G.; BARROS, F.C.; MARTINES, J.C.; BERIA, J.U.; VAUGHAN, J.P. Estudo longitudinal das crianças nascidas em 1982 em Pelotas, RS, Brasil: metodologia e resultados preliminares. Rev. Saúde públ., S. Paula, 19:58-68, 1985.

16. VICTORA, C.G.; BARROS, F.C.; VAUGHAN, J.P. Epidemiologia da desigualdade - um estudo longitudinal de 6000 crianças brasileiras. São Paulo, CEBES-Hucitec, 1988. [no prelo].

Recebido para publicação em 28/8/1987 Reapresentado em 25/5/1988 Aprovado para publicação em $6 / 6 / 1988$ 


\section{ANEXO 1}

\section{COMPOSIÇĀO DAS CLASSES SOCIAIS UTILIZADA NO PRESENTE ESTUDO. VERSÃO MODIFICADA DA PROPOSTA DE BRONFMAN E TUIRÁN*}

A burguesia está constituída por todos os proprietários de meios de produção que, sem estar eles mesmos sujeitos à exploração, empregam força de trabalho assalariada, exercendo uma função de exploração de tipo capitalista que se expressa na apropriação de uma porção de tempo de trabalho do operário. Os requisitos exigidos para pertinência a esta classe são:

a) empregar cinco ou mais pessoas; e

b) ter renda individual superior a quinze salários mínimos (pontos de corte arbitrário, porém com base nas características sócio-econômicas de Pelotas).

A nova pequena burguesia engloba os agentes sociais que ocupam os postos de mais alto nível técnico e de tomada de decisões, especificamente:

a) Os trabalhadores assalariados que desempenham, no plano econômico, funções próprias do capital, como são as de direção, organização e vigilância do processo de trabalho e da produção, como, por exemplo, os diretores de empresas, os gerentes, administradores, chefes de departamentos, e outros, que cumprem a função de organizar a exploração da força de trabalho.

b) Os trabalhadores assalariados que exercem funções de direção dentro do setor público. Este grupo é composto por agentes sociais que tem como função planejar, instrumentar e/ou executar políticas que contribuam para a reprodução das relações de produção capitalista. A alta oficialidade do exército e da polícia, os quadros diretivos da burocracia política, os legisladores, os agentes responsáveis pela execução da justiça nos tribunais, e outros, são exemplos destes agentes sociais.

c) Os trabalhadores assalariados que exercem funções as quais, apesar de não serem de direção, requerem uma formação profissional de nivel universitário. Neste grupo encontram-se os agentes que detêm o controle técnico dos meios de produção (engenheiros, cientistas, agrônomos, e outros) e aqueles cuja função é servir de veículo transmissor da ideologia dominante (jornalistas, professores, publicitários, e outros).

d) Os profissionais autônomos que são portadores de práticas especializadas que lhes permitem vender seu trabalho, ainda que não sua força de trabalho. Pertencem a este grupo agentes tais como os profissionais e técnicos que trabalham por conta própria, como médicos, engenheiros, advogados, dentistas, e outros. Estes agentes podem até possuir meios de produção e contratar mão de obra assalariada, mas difereciam-se da burguesia por empregarem menos de cinco pessoas e/ou por terem renda individual inferior a quinze salários mínimos.

A pequena burguesia tradicional é composta pelos agentes sociais que, sem possuir formação universitária, possuem a capacidade de reproduzir-se de maneira independente por disporem de meios de produção próprios. A reprodução desta classe baseia-se na utilização da força de trabalho do grupo familiar. Podem contratar força de trabalho assalariada, mas diferenciam-se dos burgueses por contratarem menos de cinco empregados e/ou por sua renda individual ser inferior a quinze salários mínimos.

Geralmente, as unidades de produção e comercialização que pertencem a esta classe operam em uma escala de reprodução simples, que lhes permite apenas recuperar o capital e o trabalho invertidos no processo. Desta forma asseguram, por uma parte, sua continuidade no processo econômico e, por outra, a reprodução de sua força de trabalho e de sua família. Este grupo encontra-se integrado pelos agentes da indústria artesanal, pelos pequenos comerciantes, e pelos proprietários independentes do setor serviços.

O proletariado inclui todos os agentes sociais que, estando submetidos a uma relação de exploração, não exercem eles mesmos nem direta nem indiretamente função de exploração. Trata-se de trabalhadores que: 1) não dispõem de meios de produção e de trabalho; 2) vendem sua força de trabalho para poder sobreviver; 3 ) são objeto da extração de uma proporção do produto de seu trabalho, e 4) não possuem formação de nível superior. De acordo com a natureza e forma concreta como os indivíduos realizam seu trabalho, distinguem-se dois diferentes subconjuntos: a) proletariado

\footnotetext{
* Bronfman, M.\& Tuirán, R. La desigualdad ante la muerte: clases sociales y mortalidad en la niñez. Cuad. méd. soc., Rosario, (29/30): 53-75, 1984.
} 
típico; e b) proletariado não-típico. No primeiro caso tratam-se de trabalhadores que desempenham atividades diretamente vinculadas com a produção e o transporte de mercadorias (pedreiros, operários, motoristas) enquanto que ao segundo grupo pertencem aqueles assalariados que somente têm relação indireta com a produção (bancários, trabalhadores de escritório, funcionários públicos).

Por último, a classe denominada subproletariado inclui todos os agentes sociais que desempenham uma atividade predominantemente não assalariada, em geral instável, com a qual obtém salários e/ou rendimentos inferiores ao custo mínimo da reprodução da força de trabalho. A esta classe pertencem:

a) Os agentes que possuem simples artefatos ou instrumentos rudimentares para desempenhar seu trabalho. Este setor caracteriza-se por operar com uma produtividade marcadamente inferior à dos padrōes vigentes, devendo vender sua escassa produção a preços que não alcançam, em geral, a retribuir o trabalho invertido nem recuperar parte do valor - capital transferido às mercadorias. Este grupo não forma parte da pequena burguesia tradicional, pois carece da solvência necessária para manter sua atividade econômica em uma escala de reprodução simples.

b) Os agentes sociais que não possuem meios de produção e que se inserem em ocupaçðes não assalariadas, predominantemente instáveis, que não exigem qualificação alguma. Este grupo encontra-se integrado por vendedores ambulantes, trabalhadores em serviços domésticos, engraxates, e outros.

c) Os agentes sociais que não possuem meios de produção e que, pela natureza do ofício que desempenham, transitam constantemente entre ocupaçōes por conta própria e ocupaçōes assalariadas não qualificadas, como os serventes da construção e empregados domésticos.

Enquanto que a classificação de Bronfman e Tuirán ${ }^{5}$ inclui tanto as classes e frações agricolas como não-agrícolas, o presente estudo limitou-se a famílias urbanas, das quais apenas $3,2 \%$ dependiam primariamente de agricultura. Estas foram incluídas nas classes ou frações não-agrícolas. Outro aspecto a destacar é a inserção da classe dos trabalhadores na indústria da construção civil, que sofreu alterações em relação ao modelo utilizado no México, conforme está detalhado no Anexo 2.

Foram consideradas como não classificáveis, 74 famílias $(1,4 \%)$, pois nos questionários constava apenas que os chefes de familia eram pensionistas, estudantes ou donas-de-casa. 


\section{ANEXO 2}

\section{ALTERAÇÕES EM RELAÇÃO À PROPOSTA DE BRONFMAN E TUIRÁN*}

As modificações realizadas no modelo de Bronfman e Tuiráns são de natureza técnica e não teórico-metodológica, e referem-se, principalmente, a algumas variáveis que não estavam disponíveis, já que a adaptação da classificação original foi feita após a coleta de dados do estudo longitudinal de Pelotas ${ }^{15,16}$. Outras modificações deveram-se às particularidades da formação econômico-social de Pelotas.

Ressalta-se que estas modificaçð̃es não descaracterizam a proposta daqueles autores, nem introduzem vícios que levem a ambigüidades na discrição de classe da pessoa de maior renda na família. Ao contrário, o modelo adaptado tem a vantagem de evidenciar que com um menor número de variáveis é possível chegar a uma operacionalização mais concisa de classe social, mais facilmente reproduzível e utilizável. Portanto, o presente modelo mantém um alto poder de discriminação de diferenciais de saúde-doença na população, sem cair em simplificações.

A seguir, estão descritas as alterações realizadas.

1. Em relação às variáveis.

Em Pelotas, não foram consideradas as seguintes variáveis:

a. Para as pessoas que trabalhavam por conta própria:

localização e tamanho do estabelecimento, propriedade de máquinas, instrumentos e instalaçðes de trabalho.

b. Para os assalariados: tamanho do estabelecimento e separação entre formação profissional e tipo de posto de trabalho.

c. Para empregadores: nível de responsabilidade na função, tipo de ocupação e propriedade de estabelecimento, maquinaria e instrumentos.

2. Em relação às características da formação econômico-social. Em Pelotas, foi criado um fluxo específico para classificar os trabalhadores na construção civil. Isto ocorreu em função das características da indústria da construção civil em nosso meio, onde há uma alta rotatividade de mãode-obra entre os serventes, que tanto podem trabalhar na construção como em outros setores de atividade, dependendo das oscilações do mercado. Por isso os serventes foram classificados como subproletários. Já os oficiais (pedreiros, azuleijistas, encanadores, parqueteiros, mestres-de-obras, e outros) são profissionais bastante disputados no mercado, geralmente encontrando-se em atividade durante todos os meses do ano, pois quando não estão empregados em obras de maior porte, trabalham em reformas ou em pequenas obras. Em função disso, foram classificados como proletários típicos.

No México, esses trabalhadores foram agrupados juntamente com outros assalariados na indústria, sendo classificados como proletários típicos.

Além disso, em Pelotas não foi utilizado um esquema exclusivo para o setor agrícola, por este apresentar um número inexpressivo, que não justificava sua classificação em separado. Os assalariados agrícolas foram incluídos no proletariado típico, pois, nessa região, as relaçôes sociais de produção no campo são tipicamente capitalistas. Os pequenos proprietários agrícolas foram incluídos na pequena burguesia tradicional, e os grandes proprietários na burguesia. $\mathrm{Na}$ classificação utilizada no México, há um quadro específico para as classes sociais agrícolas.

3. Em relação aos critérios de adscrição de classe.

a. Para os assalariados, no México, a distinção entre nova pequena burguesia e proletariado (típico e não típico) é feita com base na responsabilidade no serviço (alta/baixa), enquanto que em Pelotas considera-se a formação (universitária/não-universitária) e o tipo de função exercida (diretiva/não-diretiva).

b. Para os empregadores, em Pelotas, a distinção entre burguesia, nova pequena burguesia e pequena burguesia tradicional leva em conta apenas três variáveis (renda do chefe de família, número de empregados e formação). Ao passo que no México, a primeira variável não foi considerada, sendo usadas além das duas últimas, outras que não eram disponíveis em nossos dados.

4. Em relação a denominação das classes resultantes. "Subproletariados" foi a denominação utilizada para o que foi chamado no México de "força de trabalho livre não-assalariada"

Em Pelotas, no "proletariado típico" está agrupado o proletariado típico tanto de estabelecimentos maiores quanto de estabelecimentos menores.

* Bronfman, M. \& Tuirán, R. op. cit. 
ANEXO 3

\section{DEFINIÇÕES DE TERMOS UTILIZADOS NA PRESENTE CLASSIFICAÇÃO}

1. Estabelecimento. Foi definido como a existência de área construída que se destina exclusivamente ao exercício da atividade, podendo ser na residência ou não. Por exemplo, um armazém ou uma oficina mecânica que ocupam uma dependência da residência são considerados como estabelecimentos. Por outro lado, doceiras que utilizam a cozinha da residência ou costureiras que têm seus instrumentos de trabalho em dependências também utilizadas para outros fins, são classificadas como sem estabelecimento. Além disso, os veículos automotores usados para o exercício profissional, como táxis e caminhões de transporte de mercadorias, também são considerados estabelecimentos.

2. Conhecimento de ofício. A diferenciação entre indivíduos com e sem conhecimento de ofício foi feita tendo como base o tipo de ocupação. São incluídas aquelas que exigem anos de experiência, cujo aprendizado requer muito tempo, ou então cursos técnicos de nível médio. Como exemplo de ocupações que exigem conhecimento de ofício podemos citar eletro-técnicos, marceneiros e azuleijistas. Exemplos de ocupaçð̃es sem conhecimento de ofício seriam peões da construção civil, trabalhadores na limpeza de vias públicas, ascensoristas, e outros.

3. Indivíduos com formação universitária. São aqueles que possuem curso univesitário completo e exercem funções relacionadas com sua área de conhecimento. Por exemplo, um engenheiro civil, que seja proprietário de um armazém ou cuja ocupação principal seja a de representação comercial, não será enquadrado nesta definição. 